\title{
ANALISIS EKONOMI DAN PEMASARAN USAHATANI CABAI RAWIT DI KECAMATAN LABUHAN HAJI KABUPATEN LOMBOK TIMUR
}

\section{ECONOMIC AND MARKETING ANALYSIS OF CHILI FARMING IN LABUHAN HAJI DISTRICT EAST LOMBOK REGENCY}

\author{
Rina*;Sri**;dan Zubair** \\ *Mahasiswa Program Agribisnis, Fakultas Pertanian Universitas Mataram \\ **Dosen Fakultas Pertanian, Universitas Mataram
}

\begin{abstract}
ABSTRAK
Cabai rawit (Capsicum fritescens L.) merupakan salah satu komoditas pertanian yang banyak mendapatkan perhatian karena memiliki nilai ekonomis yang cukup tinggi karena hampir semua jenis masakan menggunakan cabai rawit untuk menambah rasa pedas pada masakan, selain itu dapat digunakan sebagai obat-obatan dan lain-lain. Penelitian ini dilakukan untuk mengetahui analisis biaya, penerimaan, pendapatan, efisiensi usahatani, saluran dan efisiensi pemasaran serta masalah yang dihadapi oleh petani cabai rawit di Kecamatan Labuhan Haji Kabupaten Lombok Timur. Penelitian ini dilaksanakan di dua Desa yaitu Desa Penedagandor dan Desa Korleko. Penelitian ini menggunakan metode deskriptif dan pengumpulan data dilakukan dengan wawancara langsung kepada petani dan ditambah dengan data pendukung lain yang dapat menunjang dari studi literatur dan pustaka. Hasil penelitian menunjukkan bahwa biaya dan pendapatan usahatani cabai rawit di Kecamatan Labuhan Haji Kabupaten Lombok Timur adalah sebesar Rp. 8.494.778/LLG atau Rp. 36.668.108/Ha dengan penerimaan sebesar Rp 48.464.917/LLG atau Rp 209.201.079/Ha dan pendapatan sebesar Rp 39.970.139/LLG atau Rp 172.532.971/Ha. R/C ratio usahatani cabai rawit di Kecamatan Labuhan Haji adalah sebesar 5,70 yang berarti bahwa usahatani cabai rawit layak untuk diusahakan karena memiliki nilai $\mathrm{R} / \mathrm{C}$ ratio $\geq 1$. Pemasaran cabai rawit sudah efisien karena share petani lebih dari $60 \%$ yaitu $66 \%$ dan $73 \%$ dengan margin $\mathrm{Rp} 11.607 / \mathrm{kg}$ dan $\mathrm{Rp} 8.654 / \mathrm{kg}$ dan distribusi keuntungan 0,78 dan 0,89. Masalah usahatani yang dihadapi oleh petani cabai rawit di Kecamatan Labuhan Haji yaitu fluktuasi harga, keterbatasan saprodi, hama dan penyakit.
\end{abstract}

Kata Kunci: Usahtani Cabai Rawit, Ekonomi, Pemasaran.

\section{ABSTRACT}

Cayenne pepper (Capsicum fritescens L.) is one of the agricultural commodities that gets a lot of attention because it has a high economic value because almost all types of cuisine use cayenne pepper to add spicy flavor to dishes, besides that it can be used as medicine and other other. This research was conducted to find out the cost analysis, revenue, income, farm efficiency, channels and marketing efficiency as well as the problems faced by cayenne farmers in Labuhan Haji District, East Lombok Regency. This research was carried out in two villages namely Penedagandor Village and Korleko Village. This study uses descriptive methods and data collection is done by direct interviews with farmers and added with other supporting data that can support the study of literature and literature. The results showed that the costs and income of cayenne farming in Labuhan Haji District, East Lombok Regency were IDR 8,494,778/LLG or IDR 36,668,108/Ha with revenues of IDR 48,464,917/LLG or IDR 209,201,079/Ha and income. amounting to IDR 39,970,139/LLG or IDR 172,532,981/Ha. R/C ratio of cayenne farming in Labuhan Haji District is 5.70, which means that chili farming is feasible because it has an $R / C$ ratio $\geq 1$. Marketing of cayenne pepper is efficient because farmers share more than 60\%, 66\% and 73\% with margins of IDR 11,607/kg and IDR 8,654/kg and distribution of profits 0.78 and0.89. Farming problems faced by cayenne farmers in Labuhan Haji District are price fluctuations, limited production inputs, pests and diseases.

Keywords: Farming Chili, Economy, Marketing. 


\section{PENDAHULUAN}

Sektor pertanian merupakan sektor primer penunjang ekonomi rakyat yang membutuhkan perhatian yang serius dari berbagai pihak agar dapat terus menopang kehidupan ekonomi sebagian besar penduduk Kabupaten Lombok Timur. Namun disisi lain, peningkatan produktivitas usahatani masih terus dihadapkan pada kendala keterbatasan biaya produksi, sempitnya lahan yang dikuasai dan terbatasnya kemampuan inovasi di samping adanya faktor eksternal lingkungan strategis makro ekonomi yang kurang mendukung keberhasilan usahatani umumnya (BPS Provinsi NTB, 2015).

Salah satu komoditas pertanian holtikultura (sayur-sayuran) yang dikembangkan adalah cabai rawit (Capsicum fritescens L.). Tanaman cabai rawit memiliki nilai ekonomis yang cukup tinggi karena hampir semua jenis masakan menggunakan cabai rawit untuk menambah rasa pedas pada masakan, selain itu dapat digunakan sebagai obat-obatan dan lain-lain.

Cabai rawit (Capsicum frutescens L) merupakan komoditas sayuran yang banyak mendapatkan perhatian karena memiliki nilai ekonomis yang cukup tinggi. Selain untuk memenuhi kebutuhan rumah tangga, permintaan akan cabai oleh industry dari hari ke hari terus meningkat, seiring dengan makin maraknya industry pengolahan bahan makanan menggunakan cabai sebagai bahan baku utamanya, misalkan sambal, saus, dan mie instan. Selain sebagai bahan industry cabai juga berperan sebagai penghasil gizi yang sangat diperlukan untuk kesehatan manusia (Anonim, 2015 dalam Wilyana, 2016.).

Tabel 1. Luas Panen, Produksi, dan Produktivitas Tanaman Cabai di NTB Tahun 2017

\begin{tabular}{lrrc}
\hline Kabupaten/Kota & Luas Panen (Ha) & Produksi (Ton) & Produktivitas (Ton/Ha) \\
\hline Kota Mataram & 27 & 166 & 6.148 \\
Lombok Barat & 205 & 1.841 & 8.980 \\
Lombok Utara & 120 & 267 & 2.225 \\
Lombok Tengah & 352 & 2.580 & 7.330 \\
Lombok Timur & 4.614 & 53.342 & 11.561 \\
Sumbawa & 152 & 1.279 & 8.414 \\
Sumbawa Barat & 21 & 30 & 1.429 \\
Dompu & 117 & 251 & 2.145 \\
Bima & 120 & 4.228 & 35.233 \\
Kota Bima & 15 & 32 & 2.133 \\
\hline Jumlah/Total & $\mathbf{5 . 7 4 3}$ & $\mathbf{6 4 . 0 1 6}$ & $\mathbf{1 1 . 1 4 7}$ \\
\hline
\end{tabular}

Sumber : BPS Provinsi NTB , *) data diolah

Kabupaten Lombok Timur merupakan salah satu penghasil cabai rawit terbesar di NTB. Berikut komoditas tanaman cabai rawit yang dihasilkan di Kabupaten Lombok Timur empat tahun terakhir dapat disajikan pada Tabel 2.

Tabel 2. Luas Panen, Produksi dan Produktivitas Cabai Rawit di Kabupaten Lombok Timur

\begin{tabular}{|l|c|c|c|c|}
\hline \multirow{2}{*}{ Cabai Rawit } & \multicolumn{4}{|c|}{ Tahun } \\
\cline { 2 - 5 } & $\mathbf{2 0 1 4}$ & $\mathbf{2 0 1 5}$ & $\mathbf{2 0 1 6}$ & $\mathbf{2 0 1 7}$ \\
\hline Luas Panen (Ha) & 4.635 & 4.619 & 4.543 & 5.861 \\
\hline Produksi (Kw) & 220.393 & 658.137 & 634.859 & 843.192 \\
\hline Produktivitas (Kw/Ha) * & 47.5497 & 142.485 & 139.744 & 143.865 \\
\hline
\end{tabular}

Sumber : BPS Provinsi NTB, *) data diolah

Tabel 2. menunjukkan bahwa selama empat tahun terakhir produksi dan produktivitas cabai rawit di Kabupaten Lombok Timur mengalami fluktuatif, hal ini disebabkan oleh banyak faktor diantaranya keterampilan petani dalam mengelola usahatani dan berbagai faktor lingku ngan lainnya. Potensi pasar cabai juga salah satu faktor yang menyebabkan produksi dan produktivitas cabai rawit berfluktuatif. Pada saat harga cabai di pasaran naik, para petani banyak yang ingin menanam cabai sehingga produksi cabai tinggi. Dilihat 
dari produksi dan produktivitas cabai rawit selama empat tahun terakhir mengalami fluktuatif karena dipengaruhi juga oleh luas panen cabai rawit.

Berikut data luas panen, produksi, dan produktivitas tanaman cabai rawit di Kabupaten Lombok Timur pada tahun 2014-2017.

Tabel 3. Luas Panen, Produksi, dan rata-rata Produksi Cabai rawit di Kecamatan Labuhan Haji 2014 - 2017

\begin{tabular}{|c|c|c|c|}
\hline \multirow{2}{*}{ Tahun } & \multicolumn{3}{|c|}{ Cabai Rawit } \\
\cline { 2 - 4 } & Luas Panen (Ha) & Produksi (Kw) & $\begin{array}{c}\text { Rata-rata } \\
\text { produksi (Ton/Ha) }\end{array}$ \\
\hline 2014 & 586 & 5.408 & 9,23 \\
\hline 2015 & 766 & 54.268 & 70,85 \\
\hline 2016 & 348 & 65.075 & 187,00 \\
\hline 2017 & 952 & 126.637 & 133,02 \\
\hline
\end{tabular}

Sumber : BPS Provinsi NTB

Tabel 3. menunjukkan bahwa produksi cabai rawit di kecamatan labuhan haji selama empat tahun terakhir produksi cabai rawit mengalami peningkatan, tetapi produktivitasnya berfluktuatif. Berfluktuasinya produktivitas cabai di daerah ini mengakibatkan pendapatan yang diterima petani juga tidak menentu. Keadaan tersebut terkait langsung dengan sering terjadinya perubahan dalam pemasaran dan juga perubahan harga cabai yang sangat fluktuatif. Menurut suaraNTB, pada bulan Maret 2017 harga cabai rawit dikisar Rp 75.000Rp 100.000 per kilogram. Dibanding pada awal bulan tahun 2017, harga cabai rawit hanya Rp 20.000Rp 21.000 per kilogram. Dan pada bulan Juli, harga cabai rawit dikisar Rp 39.838 per kilogram. Kenyataan bahwa harga cabai yang fluktuatif sering menyebabkan pendapatan petani tidak menentu.

Adapun tujuan dari penelitian ini adalah untuk: (1) untuk menganalisis biaya, penerimaan, pendapatan pada usahatani cabai rawit di Kecamatan Labuhan Haji Kabupaten Lombok Timur. (2) untuk menganalisis tingkat efisiensi usahatani cabai rawit di Kecamatan Labuhan Haji Kabupaten Lombok Timur. (3) untuk mengetahui saluran dan efisiensi pemasaran usahatani cabai rawit di Kecamatan Labuhan Haji Kabupaten Lombok Timur. (4) mengidentifikasi masalah dalam usahatanni cabai rawit di Kecamatan Labuhan Haji Kabupaten Lombok Timur.

\section{METODOLOGI PENELITIAN}

Metode yang digunakan dalam penelitian ini adalah metode deskriptif. Sedangkan pengumpulan data menggunakan teknik wawancara dengan petani responden yang berpedoman pada daftar pertanyaan. Unit analisis dalam penelitian ini adalah usahatani yang dilakukan oleh petani atau produsen cabai rawit dan lembaga pemasaran yang ikut dalam menyalurkan hasil produk (output) cabai rawit dari produsen ke konsumen akhir. Jenis data dalam penelitian ini adalah data kualitatif dan data kuantitatif. Sedangkan sumber data dalam penelitian ini yaitu data primer dan data sekunder. Penelitian ini dilaksanakan di Kecamatan Labuhan Haji Kabupaten Lombok Timur.

\section{Analisis Data}

1. Untuk mengetahui besarnya biaya yang dikeluarkan oleh petani dari usahatani cabai rawit digunakan rumus sebagai berikut:

$$
\mathrm{TC}=\mathrm{TVC}+\mathrm{TFC}
$$

Keterangan :

$\mathrm{TC}=$ Total biaya yang dikeluarkan

TVC $=$ Total biaya variabel yang dikeluarkan

TFC = Total biaya tetap yang dikeluarkan

2. Untuk mengetahui penerimaan yang diterima oleh petani dari usahatani cabai rawit digunakan rumus sebagai berikut:

$\mathrm{TR}=\mathrm{Y} . \mathrm{Py}$

Keterangan :

$\mathrm{TR}=$ Total penerimaan

$\mathrm{Y}=$ Produksi yang diperoleh dalam suatu usahatani

Py $=$ Harga $Y$ 
3. Untuk mengetahui pendapatan yang diperoleh petani dari usahatani cabai rawit digunakan rumus sebagai berikut:

$\pi=\mathrm{TR}-\mathrm{TC}$

Keterangan :

$\pi=$ Pendapatan

$\mathrm{TR}=$ Total Penerimaan (Total Revenue) $\mathrm{TC}=$

Total Biaya Produksi (Total Cost)

4. Analisis $\mathrm{R} / \mathrm{C}$

Analisis R/C ratio digunakan untuk menentukan kelayakan suatu usahatani, secara matematis dituliskan :

$R / C=\frac{\text { Revenue }(\text { Penerimaan })}{\text { Cost }(\text { Biaya Total })}$

Dengan kriteria hasil adalah sebagai berikut :

$\mathrm{R} / \mathrm{C}=1$, artinya usahatani kubis bunga pada titik impas

$\mathrm{R} / \mathrm{C}<1$, artinya usahatani kubis bunga tersebut mengalami kerugian

$\mathrm{R} / \mathrm{C}>1$, artinya usahatani kubis bunga tersebut menguntungkan.

5. Untuk mengetahui margin pemasaran usahatani cabai rawit digunakan rumus sebagai berikut:

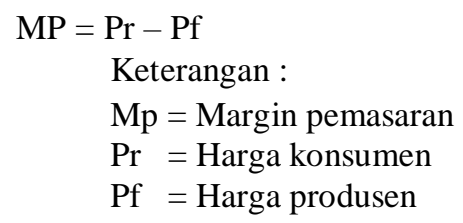

6. Untuk mengetahui share petani digunakan rumus sebagai berikut:

$$
\begin{gathered}
\mathrm{X}=(\mathrm{Pf} / \mathrm{Pr}) \times 100 \% \\
\text { Keterangan : } \\
\mathrm{X}=\text { Share yang diterima petani } \\
\mathrm{Pf}=\text { Harga produsen } \\
\mathrm{Pr}=\text { Harga konsumen }
\end{gathered}
$$

7. Untuk mengetahui distribusi keuntungan digunakan rumus sebagai berikut:

$$
\mathrm{DK}=\frac{\frac{\pi}{c} \text { terkecil }}{\frac{\pi}{c} \text { terbesar }}
$$

Keterangan :

DK $=$ Distribusi keuntunngan

$\pi$ = Pendapatan

$\mathrm{C}=$ Biaya pemasaran

\section{HASIL DAN PEMBAHASAN}

Biaya Produksi

Usahatani cabai rawit membutuhkan biaya-biaya yang digunakan selama proses produksi. Biaya-biaya tersebut meliputi biaya produksi yang terdiri atas biaya variabel dan biaya tetap. Biaya produksi merupakan total biaya yang dikeluarkan dalam satu kali produksi. Biaya produksi di dasarkan atas biaya variabel sedangkan nilai produksi merupakan penerimaan yang diperoleh dari jumlah dan harga. 
Tabel 4. Biaya Produksi Pada Usahatani cabai rawit di Kecamatan Labuhan Haji Kabupaten Lombok Timur, Tahun 2018

\begin{tabular}{|c|c|c|c|}
\hline No & Uraian & $\begin{array}{l}\text { Per LLG } \\
\text { (Rp/LLG) }\end{array}$ & $\begin{array}{l}\text { Per Hektar } \\
\text { (Rp/ha) }\end{array}$ \\
\hline \multirow[t]{5}{*}{1} & Biaya Variabel & & \\
\hline & $\begin{array}{ll}\text { a. } & \text { Sarana Produksi } \\
\text { 1) } & \text { Bibit } \\
\text { 2) } & \text { Pupuk } \\
\text { 3) } & \text { Pestisida } \\
\text { 4) } & \text { Tenaga Kerja }\end{array}$ & $\begin{array}{r}515.500 \\
559.400 \\
152.000 \\
3.338 .667\end{array}$ & $\begin{array}{r}2.225 .180 \\
2.414 .676 \\
656.115 \\
14.411 .511\end{array}$ \\
\hline & Total Biaya Variabel & 4.565 .567 & 19.707 .482 \\
\hline & \begin{tabular}{ll} 
b. & \multicolumn{2}{l}{ Biaya Lain-lain } \\
1) & Mulsa (Rp) \\
2) & Tali Rafia (Rp) \\
3) & Ajir (Rp) \\
4) & Jerami (Rp) \\
\end{tabular} & $\begin{array}{r}1.235 .000 \\
34.000 \\
2.288 .333 \\
25.000 \\
\end{array}$ & $\begin{array}{r}5.330 .935 \\
146.762 \\
9.887 .697 \\
107.913 \\
\end{array}$ \\
\hline & Total Biaya Lain-lain & 3.582 .333 & 15.463 .307 \\
\hline \multirow[t]{3}{*}{2} & Biaya Tetap & & \\
\hline & $\begin{array}{ll}\text { a. } & \text { Pajak } \\
\text { b. } & \text { Iuran Irigasi } \\
\text { c. } & \text { Penyusutan Alat }\end{array}$ & $\begin{array}{r}84.516 \\
41.833 \\
221.988\end{array}$ & $\begin{array}{l}364.820 \\
180.575 \\
958.219\end{array}$ \\
\hline & Total Biaya Tetap & 346.878 & 1.497 .319 \\
\hline 3 & Total Biaya Produksi & 8.494 .778 & 36.668 .108 \\
\hline
\end{tabular}

Sumber: Data Primer Diolah, 2018

Pada Tabel 4. tampak bahwa biaya produksi pada usahatani cabai rawit di Kecamatan Labuhan Haji Kabupaten Lombok Timur terdiri atas biaya variabel dan biaya tetap. Dari komponen biaya di atas, menunjukkan bahwa total biaya produksi yang dikeluarkan oleh petani responden yaitu sebesar Rp 8.494.778/LLG atau sebesar Rp 36.668.108/ha. Total rata-rata biaya variabel adalah sebesar Rp 4.565.567/LLG atau Rp 19.707.482/Ha dan biaya tetap sebesar Rp. 346.878/LLG atau Rp 1.497.319/Ha.

\section{Produksi, Penerimaan, dan Pendapatan}

Rata-rata produksi, penerimaan, biaya produksi, dan pendapatan usahatani cabai rawit di Kecamatan Labuhan Haji Kabupaten Lombok Timur tahun 2018 lebih jelas disajikan pada Tabel 4.14.

Tabel 5. Rata-rata Produksi, Biaya Produksi, Penerimaan, dan Pendapatan Pada Usahatani Cabai rawit di Kecamatan Labuhan Haji Kabupaten Lombok Timur, 2018

\begin{tabular}{|c|l|r|r|}
\hline No & \multicolumn{1}{|c|}{ Jenis Biaya Produksi } & Per LLG & Per Hektar \\
\hline 1 & Luas Garapan (ha) & 0,23 & 1,00 \\
2 & Produksi (kg) & 2.099 & 9.058 \\
3 & Penerimaan (Rp) & 48.464 .917 & 209.201 .079 \\
4 & Biaya Produksi (Rp) & 8.494 .778 & 36.668 .108 \\
5 & Pendapatan (Rp) & 39.970 .139 & 172.532 .971 \\
6 & R/C Ratio & 5,70 & 5,70 \\
\hline
\end{tabular}

Sumber: Data Primer Diolah, 2018

Tabel 5. menunjukkan bahwa rata-rata produksi yang diperoleh petani dalam usahatani cabai rawit di Kecamatan Labuhan Haji adalah $2.099 \mathrm{~kg} / \mathrm{LLG}$ atau sebesar $9.058 \mathrm{~kg} / \mathrm{ha}$ dengan penerimaan sebesar Rp 48.464.917/LLG atau sebesar Rp 209.201.079/ha. Selanjutnya, dengan rata-rata biaya produksi sebesar Rp 8.494.778/LLG atau Rp 36.668.108/ha diperoleh pendapatan sebesar Rp 39.970.139/LLG atau sebesar Rp 172.532.971/ha. 


\section{Analisis Kelayakan Usahatani Cabai Rawit di Kecamatan Labuhan Haji Kabupaten Lombok Timur}

Untuk mengetahui tingkat kelayakan usahatani cabai rawit di Kecamatan Labuhan Haji Kabupaten Lombok Timur dapat dianalisis usahataninya dari aspek ekonomi dengan menggunakan R/C ratio. $\mathrm{R} / \mathrm{C}$ ratio merupakan Revenue/Cost dimana penerimaan sebagai Revenue dan total biaya produksi sebagai cost. Suatu usahatani dianggap layak apabila $\mathrm{R} / \mathrm{C}$ ratio besar dari 1 atau sama dengan 1, apabila $\mathrm{R} / \mathrm{C}$ ratio kecil dari 1 maka usahatani tersebut dikatakan rugi.

Tabel 6. Penerimaan, Biaya Produksi, Pendapatan dan Efisiensi Usahatani cabai rawit di Kecamatan Labuhan Haji Kabupaten Lombok Timur, 2018

\begin{tabular}{|l|l|r|r|}
\hline No & \multicolumn{1}{|c|}{ Uraian } & Per LLG & \multicolumn{1}{c|}{ Per Ha } \\
\hline 1 & Penerimaan & 48.464 .917 & 209.201 .079 \\
2 & Total Biaya Produksi & 8.494 .778 & 36.668 .108 \\
3 & Pendapatan & 39.970 .139 & 172.532 .971 \\
\hline \multicolumn{1}{|c|}{ R/C-ratio } & 5,70 & 5,70 \\
\hline
\end{tabular}

Sumber: Data Primer Diolah, 2018

Selain biaya dan pendapatan, efisensi merupakan hal yang penting dalam sebuah usahatani. Efisiensi usahatani dilihat melalui perbandingan penerimaan yang diperoleh dengan biaya yang dikeluarkan. Nilai R/C ratio dari usahatani cabai rawit adalah 5,70 artinya setiap Rp. 1,00 biaya yang dikeluarkan dalam usahatani tersebut akan menghasilkan penerimaan sebesar Rp. 5,70. Nilai R/C sebesar 5,70>1 dapat disimpulkan bahwa usahatani cabai rawit di daerah penelitian layak diusahakan atau dengan kata lain menguntungkan

\section{Analisis Efisiesni Pemasaran}

Efisiensi pemasaran adalah kemampuan dari produsen serta rantai atau lembaga pemasaran dalam menyampaikan produksi kepada konsumen dengan harga yang wajar tanpa merugikan kepentingan sebagian pihak yang terlibat dalam kegiatan pemasaran (Mubyarto, 1989).

Suatu pemasaran dikatakan efisien apabila memenuhi indikator yaitu harga yang diterima petani cabai rawit lebih besar dari 60\%, dan margin pemasaran yang lebih kecil. Untuk mengetahui saluran pemasaran yang dikatakan efisien dari satu saluran pemasaran cabai rawit di kecamatan Labuhan Haji dapat dilihat pada Tabel 7. berikut:

Tabel 7. Share Petani, Margin Pemasaran, dan Distribusi keuntungan Cabai Rawit di Kecamatan Labuhan Haji 2018

\begin{tabular}{|l|l|c|c|}
\hline No & \multicolumn{1}{|c|}{$\begin{array}{c}\text { Indikator saluran } \\
\text { Pemasaran }\end{array}$} & $\begin{array}{c}\text { Saluran } \\
\text { Pemasaran I }\end{array}$ & $\begin{array}{c}\text { Saluran } \\
\text { Pemasarn II }\end{array}$ \\
\hline 1. & Share Petani $(\%)$ & 66,03 & 73,15 \\
\hline 2. & Margin Pemasaran & 11607,00 & 8654,00 \\
\hline 3. & Distribusi Keuntungan & 0,78 & 0,89 \\
\hline & Kriteria Keputusan & Efisien & Efisien \\
\hline
\end{tabular}

Sumber: Data Primer Diolah, 2018

Tabel 4.18 menunjukkan bahwa share petani pada saluran I sebesar $66 \%$ dan pada saluran II sebesar 73\%. Margin pemasaran saluran I sebesar Rp $11.607 / \mathrm{kg}$ dan saluran II sebesar Rp. 8.654/kg. Margin pemasaran saluran II lebih rendah dari saluran I karena pada saluran pemasaran I merupakan saluran terpanjang. Distribusi keuntungan saluran pemasaran I sebesar 0,78 dan saluran pemsaran II sebesar 0,89. Jadi pemasaran cabai rawit di Kecamatan Labuhan Haji Kabupaten Lombok Timur dapat dikatakan efisien.

\section{Masalah yang dialami Petani dalam Melakukan Usahatani Cabai Rawit di Kecamatan Labuhan Haji Kabupaten Lombok Timur}

Dalam pelaksanaan usahatani cabai rawit di Kecamatan Labuhan Haji, terdapat beberapa masalah yang dihadapi petani, baik masalah teknis maupun ekonomi. Masalah yang dihadapi petani antara lain yaitu hama dan penyakit, keterbatasan saprodi, harga yang fluktuatif.

Masalah yang sering dihadapi yaitu masalah hama dan penyakit yang menyerang cabai rawit tersebut. Berdasarkan hasil penelitian diketahui, 10 petani responden atau 33,3\% yang menyatakan serangan hama dan penyakit dapat menurunkan produksi cabai rawit. Penyakit yang sering menyerang yaitu busuk batang dan 
busuk daun. Penyebab penyakit busuk batang dan busuk daun adalah bibit yang digunakan kurang bagus. Adapun cara pengendalian hama penyakit yang diterapkan petani responden untuk menghindari terjadinya penurunan produksi dan kegagalan panen adalah dengan cara memotong batang dan daun cabai yang terserang hama penyakit busuk batang dan busuk daun. Segera ganti tanaman yang terserang hama penyakit agar tanaman yang lainnya tidak terkena hama penyakit. Obat yang bisa digunakan adalah greentonik dan antracol.

Selain itu salah satu masalah yang dihadapi yaitu sarana produksi seperti pupuk, sebanyak 5 responden atau 16,6\% di mana sarana produksi yang dimaksud adalah kurangnya ketersediaan pupuk yang masuk karena pedagang kurang mensuplay sarana produksi salah satunya pupuk. Adapun cara yang diterapkan petani responden untuk menghindari kurangnya sarana produksi yaitu petani melakukan kerjasama dengan petani yang lain dengan cara memesan langsung di agen tempat pembelian sarana produksi sehingga mengantarnya langsung ke petani atau menitip sarana produksi di masyarakat setempat yang tujuannya sama.

Harga cabai rawit sangat menentukan pendapatan yang dipeoleh petani, semakin tinggi harga cabai rawit maka pendapatan petani akan semakin besar, sebaliknya semakin rendah harga

cabai rawit maka pendapatan petani akan semakin kecil. Harga cabai rawit di tentukan oleh kebutuhan konsumen, semakin banyak permintaan cabai rawit maka harganya akan tinggi, sebaliknya semakin berkurang permintaan cabai rawit maka harganya akan rendah.

\section{KESIMPULAN DAN SARAN}

\section{Kesimpulan}

Berdasarkan pada hasil penelitian dan pembahasan yang telah diuraikan sebelumnya, maka dapat ditarik kesimpulan sebagai berikut:

1. Usahatani cabai rawit di Kecamatan Labuhan Haji sangat menguntungkan. Rata-rata biaya usahatani cabe rawit sebesar Rp 8.494.778/LLG atau sebesar Rp 36.668.108/Ha dengan rata- rata produksi cabai rawit sebesar $2.099 \mathrm{Kg} / \mathrm{LLG}$ atau sebesar $9.058 \mathrm{Kg} / \mathrm{Ha}$. Rata-rata penerimaan petani adalah sebesar $\mathrm{Rp}$ 48.464.917/LLG atau Rp 209.201.079/Ha. Rata-rata pendapatan petani adalah sebesar Rp 39.970.139/LLG atau Rp 172.532.971/Ha.

2. Nilai R/C perluas lahan garapan sebesar 5,70 maka usahatani cabai rawit tergolong layak untuk diusahakan karena $\mathrm{R} / \mathrm{C}>1$.

3. Terdapat dua saluran pemasaran cabe rawit di Kecamatan Labuhan Haji Kabupaten Lombok Timur, yaitu: saluran pemasaran I (Petani $\rightarrow$ Pedagang Pengepul $\rightarrow$ Pedagang Pengepul Kecamatan $\rightarrow$ Pengecer $\rightarrow$ Konsumen), saluran pemasaran II (Petani $\rightarrow$ Pedagang Pengepul $\rightarrow$ Pengecer $\rightarrow$ Konsumen). Ke dua saluran pemasaran cabai rawit dapat dikatakan efisien karena memiliki share petani yaitu sebesar 66\% dan 73\%, Margin pemasaran yaitu sebesar Rp 11.607 dan Rp 8.654, dan Distribusi keuntungan sebesar 0,78 dan 0,89 .

4. Masalah yang dihadapi petani cabe rawit di Kecamatan Labuhan Haji adalah fluktuasi harga, keterbatasan saprodi, hama dan penyakit.

Saran

Saran yang dapat diberikan:

1. Disarankan kepada para petani untuk mengatur pola tanam di mana pada saat panen harga cabai bisa lebih tinggi.

2. Pemerintah lebih berperan aktif dalam melakukan pembinaan pada masalah yang dihadapi petani sehingga dapat membantu meberikan solusi seperti pengendalian hama penyakit dan penyediaan sarana produksi.

\section{DAFTAR PUSTAKA}

Badan Pusat Statistik Provinsi NTB. 2015. Nusa Tenggara Barat Dalam Angka 2015. Badan Pusat Statistik. Mataram.

Mubyarto. 1989. Pengantar Ekonomi Pertanian. LP3ES. Jakarta.

Soekartawi. 1995. Analisis Usahatani. Penerbit Universitas Indonesia. Jakarta.

Wilyana, E. 2016. Analisis Rantai Nilai Pemasaran Cabai Rawit di Kecamatan Suralaga Kabupaten Lombok Timur. Dalam Skripsi Fakultas Pertanian Universitas Mataram. Mataram.

Sofanudin, A dan Budiman E, Y. 2017. Pemasaran Sari Buah Blimbing (di P4S Cemara Sari Desa Karangsari). Jurnal Variabel Pertanian Volume 11 No 1. 